\title{
SINERGISME PENGARUH PENGEMBANGAN KARIER DAN IKLIM ORGANISASI MELALUI MODERASI MOTIVASI KERJA TERHADAP IMPLEMENTASI GOOD GOVERNANCE SEKRETARIAT DPRD DALAM WILAYAH SUMATERA SELATAN
}

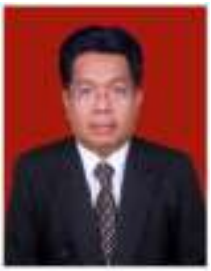

Oleh :

Dr. Fakhry Zamzam, M.M

\begin{abstract}
ABSTRAK
Penelitian ini ditujukan untuk melihat faktor-faktor yang memengaruhi implikasi prinsipprinsip good governance Sekretariat Dewan Perwakilan Rakyat Daerah dalam wilayah Sumatera Selatan.

Penelitian ini menggunakan metode survey konfirmatif bersifat deskriptif verifikatif. Analisis data menggunakan statistika deskriptif dan statistika inferensial Populasi dan sampel penelitian menggunakan sampel jenuh. Metode analisis menggunakan Structural Equation Modeling (SEM). Pengujian hipotesis dilakukan dengan menggunakan program AMOS version 20.

Hasil penelitian menunjukkan bahwa ; Iklim organisasi tidak memengaruhi motivasi kerja dengan signifikansi $(\mathrm{P})$ 0,725 $>0,05$ dan nilai CR sebesar $-0,352<1,96$, pengembangan karir memengaruhi motivasi kerja dengan signifikansi $(\mathrm{P}) * * *<0,05$ dan nilai CR sebesar $3.666>1,96$, iklim organisasi dan pengembangan karir secara bersama-sama memengaruhi motivasi kerja, dengan output squared multiple correlations $19,9 \%$, Iklim organisasi memengaruhi good governance dengan signifikansi $(\mathrm{P})$ 0,043 < 0,05 dan CR $2.023>1,98$, pengembangan karir memengaruhi good governance dengan tingkat signifikansi $(\mathrm{P}) 0,001<0,05$ dan nilai CR 3,266 > 1,96, motivasi kerja memengaruhi good governance dengan signifikansi 0,022 < 0,05 dan CR nilai 2,286 > 1,96, iklim organisasi, pengembangan karir dan motivasi kerja secara bersama-sama memengaruhi good governance, sesuai output squared multiple correlations determinasi 43,5\%

Rekomendasi penelitian perlu melakukan penelitian untuk mengetahui pengaruh variasi variabel diluar penelitian yang memengaruhi good governance Sekretariat DPRD, Semoga !
\end{abstract}

Kata kunci ; Good Governance, Pengembangan karier, iklim oraginsasi dan motivasi kerja.

\section{A. LATAR BELAKANG}

Penelitian Assosiasi Sekretaris

DPRD Kabupaten dan Kota se-Indonesia (ASDEKSI) tahun 2007, priode tahun 2004-2007 setiap 9 hari di Indonesia seorang Sekretaris DPRD diganti. Sementara di Provinsi Sumatera Selatan dalam priode yang sama, setiap 37 hari seorang Sekretaris DPRD dimutasi.

Betapa rentannya jabatan Sekretaris DPRD setiap saat harus siap menerima resiko dimutasi. Tingginya frekwensi pergantian Sekretaris DPRD, memberi pengaruh memengaruhi motivasi kerja pejabat, pada gilirannya akan memberikan implikasi memengaruhi implementasi prinsip-prinsip good governance.

Dalam konteks pengelolaan keuangan, dilematis bagi Sekretaris DPRD ketika dihadapkan permintaan DPRD dalam menggunakan anggaran untuk kepentingan subjektif. Masih ada anggapan bahwa anggaran DPRD 
merupakan hak yang dapat digunakan sesuai keinginan dan kepentingan DPRD.

Sekretariat DPRD menjadi tempat interaksi antara legislasi dan eksekutif, sehingga atmosfir pada Sekretariat DPRD selalu beraroma kepentingan politis. Dalam mengelola anggaran selalu berlangsung tarik menarik kepentingan antara legislatif dan eksekutif, menyebabkan pengelolaan keuangan belum dapat akuntabel ditandai dengan tingginya kerugian negara.

Iklim organisasiSekretariat DPRD seperti ini menjadi kurang kondusif dan dapat menurunkan motivasi kerja pejabat dalam menjalan prinsip-prinsip good governance. Adanya Intervensi DPRD dalam pengelolaan keuangan, menyebabkan sulit menghindari pelanggaran ketentuan. Sementara ketentuan pengelolaan keuangan daerah yang akan dimintakan pertanggungjawaban adalah pengguna anggaran yaitu pejabat Sekretaris DPRD.

Praktik penggunaan anggaran DPRD menjadi persoalan dalam mengimplementasikan good governance. Menjadi dilematis ketika pejabat Sekretaris DPRD menolak keinginan DPRD, maka akan dituding tidak mendukung DPRD, sebaliknya jika memenuhi akan berimplikasi terhadap persoalan hukum.

Penomena akuntabilitas pengelolaan keuangan daerah di Sumatera Selatan tergambar dalam tabel berikut ini.

Tabel Akuntabilitas Keuangan Daerah di Sumatera Selatan

\begin{tabular}{|c|c|c|c|c|c|}
\hline \multirow{3}{*}{ No } & \multirow{3}{*}{ Pemerintah Daerah } & \multicolumn{4}{|c|}{ Periode Pemeriksaan BPK } \\
\hline & & \multicolumn{2}{|c|}{ Tahun 2008} & \multicolumn{2}{|c|}{ Tahun 2009} \\
\hline & & Kasus & Besaran & Kasus & Besaran \\
\hline 1 & Sumatera Selatan & 60 & $48.553,64$ & 40 & $25.571,84$ \\
\hline 2 & Kota Palembang & 50 & $8.428,18$ & 57 & $8.028,06$ \\
\hline 3 & Kota Pagar Alam & 36 & $1.566,91$ & 18 & $1.364,90$ \\
\hline 4 & Kota Prabumulih & 20 & $6.980,10$ & 26 & $10.420,35$ \\
\hline 5 & Kota Lubuk linggau & 21 & $3.952,83$ & 29 & $12.923,27$ \\
\hline 6 & Kabupaten Muba & 36 & $3.889,04$ & 43 & $255.012,09$ \\
\hline 7 & Kab. Banyuasin & 32 & $3.644,90$ & 29 & $5.883,71$ \\
\hline 8 & Kabupaten OKU & 22 & $4.598,40$ & 60 & $7.751,49$ \\
\hline 9 & Kabupaten OKUT & 29 & $2.229,72$ & 15 & 468,06 \\
\hline 10 & Kabupaten OKUS & 43 & $6.403,20$ & 30 & $5.662,15$ \\
\hline 11 & Kabupaten OKI & 11 & 588,69 & 29 & $3.808,50$ \\
\hline 12 & Kabupaten OI & 13 & $13.642,66$ & 24 & $3.867,61$ \\
\hline 13 & Kabupaten Lahat & 21 & 376,09 & 41 & $1.809,35$ \\
\hline 14 & Kab. 4 Lawang & - & - & 28 & $2.371,16$ \\
\hline 15 & Kabupaten Mura & 34 & $2.308,05$ & 33 & $1.671,45$ \\
\hline 16 & Kab. Muara Enim & 21 & 552,62 & 48 & $1.023,95$ \\
\hline
\end{tabular}

Sumber : BPK Perwakilan Palembang, 2012 
Besarnya hasil atensi BPK atas laporan keuangan daerah di atas, menggambarkan bahwa dalam priode 2008 dan 2009 banyak pelanggaran ketentuan pengelolaan keuangan berdampak dan memengaruhi pertanggungjawaban keuangan.

\section{Rumusan Masalah}

1) Apakah iklim organisasi berpengaruh terhadap motivasi kerja Sekretaris DPRD?

2) Apakah pengembangan karir berpengaruh terhadap motivasi kerja Sekretaris DPRD?

3) Apakah iklim organisasi dan pengembangan karir secara bersamasama berpengaruh terhadap motivasi kerja Sekretaris DPRD?

4) Apakah iklim organisasi berpengaruh terhadap implementasi good governance Sekretariat DPRD?

5) Apakah pengembangan karir berpengaruh terhadap good governance Sekretaris DPRD?

6) Apakah motivasi kerja berpengaruh terhadap good governance Sekretariat DPRD?

7) Apakah iklim organisasi, pengembangan karir dan motivasi kerja secara bersama-sama berpengaruh terhadap good governance Sekretariat DPRD?

\section{Teori Iklim Organisasi}

$R$ Tagiuri dan $G$ Litwin dalam Wirawan (2007:121), mengemukakan sejumlah istilah untuk melukiskan perilaku dalam hubungan dengan latar atau tempat (setting) dimana perilaku muncul, lingkungan (environment), lingkungan pergaulan (milieu), budaya (culture), suasana (atmosphere), situasi (situation), pola lapangan (field setting), pola perilaku (behavior setting) dan kondisi (conditions).

Pendapat Wirawan (2007:122) iklim organisasi akan menentukan kinerja anggota organisasi, memberikan definisi tentang iklim organisasi adalah persepsi anggota organisasi (secara individu dan kelompok) dan mereka yang secara tetap berhubungan dengan organisasi mengenai apa yang ada atau terjadi di lingkungan internal organisasi dan kinerja anggota organisasi yang kemudian menentukan kinerja organisasi.

Dengan adanya suasana kerja yang nyaman dan tenang tersebut memungkinkan pegawai untuk bekerja lebih baik, lingkungan organisasi akan kondusif bila memperhatikan kebutuhan dan kenyamanan bawahan. Pada satu sisi memang butuh pemimpin yang mampu membuat tata nilai dan sistem kerja yang baik, akan tetapi pada sisi lain harus memperhatikan kebutuhan bawahan sehingga akan terbangun mutualitas.

Dari beberapa definisi tentang iklim organisasi yang telah dikemukan para pakar di atas, dapat ditarik sintesis variabel iklim organisasi yang digunakan dalam peneltian ini adalah : "lingkungan kerja internal yang dipengaruhi oleh lingkungan eksternal organisasi yang secara relatif berlangsung terus menerus sehingga mewarnai suasana kerja, baik langsung ataupun tidak langsung akan mempengaruhi pola hubungan kerja, pola komunikasi kerjadan kenyamanan kerja hingga motivasi kerja anggata organisasi”.

\section{Teori Pengembangan Karir}

Pengembangan karir (career development) merupakan suatu proses yang dimulai dari perencanaan karir (career planning) yang impelementasinya dalam manajemen karir (career 
Management). Pengembangan karir dalam organisasi ditentukan oleh interaksi perencanaan karir dengan manajemen karir dalam suatu organisasi.

Pengertian pengembangan karir menurut Noe Raymond and Barry (2003:303), adalah " a formal approach taken by an organization to ensure that people white the proper qualifications and experience are available when needed".

Menurut Andrew J. Fubrin dalam Mangkunegara (2009:77) "career development, from the standpoint of the organization, is the personnel activity which helps individuals plans their future career within the enterprise, in order to help the enterprise achieve and the employee achive maximum selfdevelopment".

Moeheriono pengembangan karir itu sendiri merupakan arah atau jalur-jalur serta pilihan yang akan memberikan kepada setiap karyawan untuk mengembangkan karirnya sepanjang arah itu mencerminkan tujuan dan kemampuannya. Pilihan arah yang ingin dikembangkan merupakan kesempatan yang baik bagi karyawan itu sendiri di manapun dan kapanpun.

Dari pendapat pakar di atas, dapat dirumuskan sintesis pengembangan karir adalah : "implementasi perencanaan karir didasarkan atas kompetensi jabatan dan jenjang karir, sebagai upaya individu untuk mengembangkan kemampuan yang terintegrasi dengan kebutuhan organisasi menuju kehidupan organisasi yang lebih baik".

\section{Teori Motivasi kerja}

Pengertian motivasi, seperti yang dikemukakan oleh Wexley dan Yuki adalah pemberian atau penimbunan motif. Jadi motivasi kerja adalah suatu yang menimbulkan semangat atau dorongan kerja. Itulah sebabnya, motivasi kerja dalam psikologi karya biasa disebut pendorong semangat kerja. Kuat dan lemahnya motivasi kerja seseorang ikut menentukan besar kecilnya prestasi orang tersebut.

Gray dalam Winardi (2008:2) memberikan definisi tentang motivasi bahwa motivasi merupakan hasil sejumlah proses yang bersipat internal bagi seseorang individu yang menyebabkan timbulnya sikap entusiasme dan persistensi dalam hal melaksanakan kegiatan-kegiatan tertentu.

Mengacu kepada teori kebutuhan untuk mencari prestasi dari David Mc Clelland (Mangkunegara, 2009: 97,98) tiga macam kebutuhan manusia, yaitu :

(1) Need for achievement, yaitu kebutuhan untuk berprestasi yang merupakan refleksi dari dorongan akan tanggung jawab untuk pemecahan masalah.

(2) Need for affiliation, yaitu kebutuhan untuk berafiliasi yang merupakan dorongan untuk berinteraksi dengan orang lain dan berada bersama orang lain.

(3) Need for power, yaitu kebutuhan untuk kekuasaan yang merupakan refleksi dari dorongan untuk mencapai otoritas untuk memiliki pengaruh memengaruhi orang lain.

Maka dapat dirumuskan sintesis motivasi kerja dalam penelitian ini adalah: "suatu daya dorong yang bersumber dari diri seorang pejabat, berupa keinginan memenuhi kebutuhan atau daya tarik yang berasal dari lingkungan eksternal yang melatar belakangi pejabat untuk melakukan afiliasi, membuat prestasi kerja dan menjalankan kewenangan dan tanggungjawab". 


\section{Teori Good Governance}

UNDP (2008) mendefinisikan governance sebagai "the exercise of political, economic and administrative authority to manage a nation affair at all level" definisi yang diberikan oleh UNDP (2008) lebih baik karena menggunakan kata "authority" yang diartikan sebagai kewenangan bukan "power".

Pelaksanaan good governance, mendasarkan 9 prinsip dasar, yang disebut Prinsip-prinsip good governance yang telah dikembangkan di Indonesia, yaitu : participation, rule of law, transparency, responsiveness, consensus orientation, equity, effectiveness \& efficiency, accountability, dan strategic vision.

Prinsip-prinsip good governance (Sedarmayanti, 2007:38,39) sesungguhnya saling memperkuat tidak dapat berdiri sendiri, terdapat 4 prinsip utama yaitu :

(1) Akuntabilitas, setiap kegiatan dan hasil akhir dari kegiatan penyelenggaraan negara harus dapat dipertanggungjawabkan kepada masyarakat sebagai pemegang kedaulatan.

(2) Transparansi, kepemerintahan yang baik bersipat transparan memengaruhi rakyatnya, baik di tingkat pusat maupun di daerah

(3) Keterbukaan, membuka diri memengaruhi hak masyarakat untuk memperoleh informasi yang benar dan jujur serta tidak diskriminatif.

(4) Aturan Hukum, mengutamakan landasan peraturan perundangundangan, kepatutan dan keadilan dalam setiap kebijakan penyelenggaraan negara.

Dari pendapat pakar mengenai di atas, dirumuskan sintesisnya bahwa good governance adalah: "praktek penyelenggaraan pemerintahan daerah yang bertanggung jawab, dalam mengelola berbagai sumber-sumber secara terbuka dan transparan serta patuh menjalankan ketentuan perundangan-undangan".

\section{Kerangka Pemikiran}

Iklim organisasi yang kondusif dapat membangun hubungan kerja yang harmonis, sehingga akan mendorong motivasi kerja. Pengembangan karir yang berjalan baik menjadi daya dorong motivasi kerja. Begitu juga iklim organisasi yang nyaman dengan pengembangan karir yang jelas, secara bersama-sama akan memengaruhi peningkatan motivasi kerja.

Rofiatun dan Masluli (2011) mengatakan bahwa "there is a significant positive effect between the Organization of the motivational climate proved, because the CR value of 3.205 with $P$ value of 0.001 "

Motivasi kerja seseorang berupa usaha untuk mencapai prestasi, termasuk di dalamnya untuk mengelola tata pemerintahan yang baik. Sehingga motivasi kerja akan dapat meningkatkan kinerja organisasi, keberhasilan menjalankan implementasi prinsip-prinsip good governance merupakan suatu prestasi dan kinerja.

Iklim organisasi dan motivasi kerja mempunyai hubungan positif, semakin baik iklim organisasi akan dapat meningkatkan motivasi kerja, ini hasil penelitian yang dilakukan Bhattacharya (2013) in conclusion it can be said that there is a positive relationship between organizational climate and work motivation as expressed by the employees of private sector organization.

Pendapat di atas sejalan dengan penelitian Suherman, Herlan (2005), 
bahwa variabel pengembangan karir memberikan pengaruh positif secara signifikan terhadap variabel motivasi kerja dan kinerja karyawan.

Begitu pula dengan iklim organisasi yang kondusif akan membuat pejabat merasa nyaman dalam menjalankan tata kelola pemerintahan yang baik. Adanya jaminan pengembangan karir tanpa diskriminatif dapat memotivasi anggota organisasi dalam menjalankan prinsipprinsip good governance.

Kerangka pemikiran di atas, diangkat dari pemahaman bahwa iklim organisasi dan pengembangan karir secara bersama-sama akan memengaruhi peningkatan motivasi kerja. Iklim organisasi, pengembangan karir dan motivasi kerja, secara bersama-sama akan memberikan implikasi terhadap implementasi good governance Sekretariat DPRD.

Motivasi kerja untuk berprestasi akan menghasilkan kinerja baik, seperti halnya dorongan untuk menjalankan prinsip-prinsip good governance. Pendapat ini didukung penelitian yang dilakukan oleh Suaidi, Alif (2010) yang menyimpulkan bahwa motivasi kerja pegawai dapat memengaruhi penerapan good governance, terdapat hubungan yang berarti antara variabel kepemimpinan dengan variabel motivasi pegawai Direktorat Jenderal Imigrasi menuju penerapan good governance.

Hasil penelitian yang dilakukan oleh Suherman, Herlan (2009), menyimpulkan penelitiannya bahwa "variabel pengembangan karir memberikan pengaruh positif secara signifikan terhadap variabel motivasi kerja dan good governance karyawan".

Seseorang akan bekerja lebih baik apabila mereka merasakan bahwa apa yang mereka lakukan dihargai dan diberikan suatu imbalan atau ganjaran, pendapat Sunyoto, Danang (2012:182) di atas menegaskan bahwa pejabat akan melaksanakan good governance perlu didorong oleh adanya motivasi seperti mendapatkan kompensasi atau insentif tertentu.

Kerangka pemikiran penelitian di atas digambarkan dalam alur pikir penelitian sebagai berikut ini.

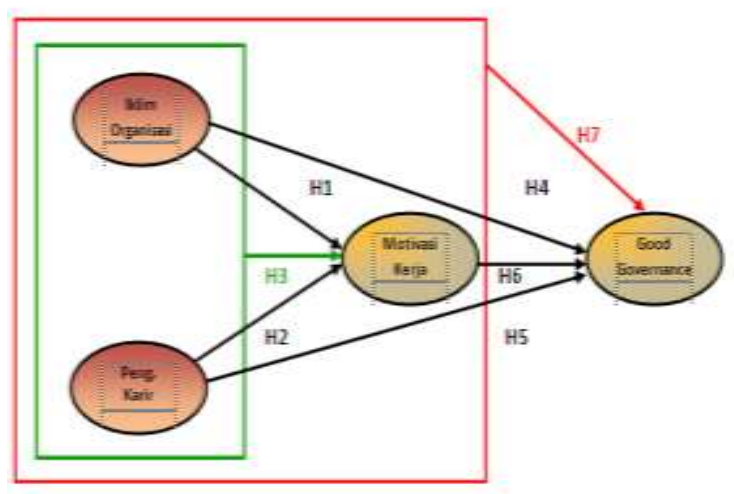

\section{Bagan Kerangka Teoritik Penelitian Hipotesis Penelitian}

1) Iklim organisasi memengaruhi motivasi kerja Sekretaris DPRD.

2) Pengembangan karir memengaruhi motivasi kerja Sekretaris DPRD.

3) Iklim organisasi dan pengembangan karir secara bersama-sama memengaruhi motivasi kerja pejabat Sekretaris DPRD.

4) Iklim organisasi memengaruhi good governance Sekretariat DPRD.

5) Pengembangan karir memengaruhi good governance Sekretariat DPRD.

6) Motivasi kerja memengaruhi good governance Sekretariat DPRD.

7) Iklim organisasi, pengembangan karir dan motivasi kerja secara bersamasama memengaruhi good governance. 


\section{Metodelogi Penelitian}

Penelitian ini menggunakan metode survey konfirmatif bersifat deskriptif verifikatif. Analisis data menggunakan statistika deskriptif dan statistika inferensial Populasi dan sampel penelitian menggunakan sampel jenuh, seluruh pejabat struktural pada 16 Sekretariat DPRD di Provinsi Sumatera Selatan, adalah populasi dan sampel penelitian.

\section{Sumber dan Pengumpulan Data}

Jenis data terdiri dari sumber data primer dan sumber data sekunder. Data primer bersumber dari jawaban kuesioner dan melakukan wawancara. Sedangkan data sekunder untuk penelitian penelitian ini diperoleh dari berbagai sumber

Pengumpulan Data menggunakan metode kuesioner dengan membuat instrumen penelitian dan metode wawancara kepada nara sumber yang berkompeten pada bidang yang diteliti

\section{Metode Analisis Data}

Metode analisis yang digunakan dalam penelitian ini menggunakan Structural Equation Modeling (SEM). SEM merupakan teknik multivariate yang mengkombinasikan aspek regresi berganda dan analisis faktor untuk mengestimasi serangkaian hubungan ketergantungan secara simultan (Hair et al, 2008). Pengujian hipotesis dilakukan dengan menggunakan program AMOS version 20.

\section{Asumsi Dasar SEM}

Sebelum melakukan pengujian model struktural dengan pendekatan SEM yang menggunakan estimate maximum likelihood, ada beberapa asumsi dasar yang harus dipenuhi terlebih dahulu yaitu : Data Kontinous Interval, Penelitian ini menggunakan Skala Likert untuk mendapatkan data kontinous interval. Menurut Uma Sekaran Skala Likert akan menghasilkan data interval.

Asumsi Kecukupan Sampel Besaran ukuran sampel memiliki peran penting dalam interpretasi hasil analisis SEM. Ukuran sampel minimal menurut Hair et.al seperti dikutif oleh Ferdinand (2002:43) yang menyatakan bahwa ukuran sampel (data observasi) yang sesuai adalah berjumlah antara 100 sampai 200 atau minimal menggambarkan perbandingan 5 dan maksimal 10 yakni 100 sampai 200.

Uji Normalitas, SEM mensyaratkan data terdistribusi normal, data distribusi normal jika angka cr skweness atau angka cr kurtoses ada di antara -2,58 sampai +2,58 (Santoso Singgih 2011:78,79).

Asumsi Outliers, Outliers adalah observasi atau data yang memiliki karakteristik unik yang terlihat sangat berbeda jauh dari observasi-observasi lainnya dan muncul dalam bentuk nilai ekstrim, baik untuk sebuah variabel tunggal atau variabel kombinasi (Hair et al. dalam Ferdinand, 2002: 97).

Asumsi Linearitas, Uji linearitas bertujuan untuk mengetahui apakah dua variabel mempunyai hubungan yang linear. Pengujian pada SPSS dengan menggunakan test for linearity dengan pada taraf signifikansi 0,05 . Dua variabel dikatakan mempunyai hubungan yang linear bila signifikansi linearity kurang dari 0,05 .

\section{Analisis Structural Equation Modelling}

Model persamaan struktural (structural equation modelling) menurut Bagozzi dan Fornell dalam (Ghozali 2005:3) memungkinkan peneliti untuk menguji hubungan antar variabel yang kompleks baik recurcive maupun non- 
recurcive untuk memperoleh gambaran menyeluruh mengenai keseluruhan model.

Penelitian menggunakan dua macam teknik analisis yaitu : Analisis faktor konfirmatori (confirmatory factor analysis), regression weightdan Squared Multiple Corelation sebagai

\section{Langkah SEM}

Hair et. al dalam Ghozali (2013:61) mengajukan tahapan permodelan dan analisis persamaan struktrural menjadi 7 (langkah) yaitu

1) pengembangan model Berdasar teoritis,

2) menyusun diagramjalur (path diagram),

3) mengubah diagram jalur menjadi persamaan struktural,

4) memilih matrik input untuk amalisis data,

5) menilai idenfikasi model,

6) mengevaluasi estimasi model dan

7) interpretasi memengaruhi model.

\section{Analisis dan Pembahasan}

\section{Analisis Statistika Deskriptif}

Deskripsi variabel iklim organisasi

Sekretariat DPRD, rata-rata jawaban adalah 3.7602. Tertinggi pada pernyataan Io.06. Komunikasi kerja berlangsung dengan kondusif koefisien 3.9721. Terendah pernyataan Io.05 Pertemuan rutin antaraSekretaris DPRD dan DPRD telah berjalan koefisien 3.4302 .

Deskripsi variabel pengembangan karier rata-rata jawaban 3.8367. Item pernyataan mendapatkan jawaban tertinggi adalah pada Pk.07 "Semua pejabat memiliki kesempatan karir yang sama" sebesar 4.2011 dan pernyataan terendah adalah Pk.02 Sistem karir pejabat berjalan sesuai ketentuan dengan koefisien sebesar 3.4134 .
Deskripsi variabel motivasi kerja mengindikasikan rata-rata jawaban adalah 4.1086. Jawaban tertinggi pada pernyataan Mk.11 "Profesionalisme kerja pejabat lebih dihargai" sebesar 4.3128 dan terendah adalah Mk.09 Pejabat mampu mengakomodasi kepentingan DPRD sebesar 3.8045.

Deskripsi atas variabel good governance rata-rata jawaban koefisien 3.8971. Jawaban tertinggi pada pernyataan Gg.07 "Pemahaman tugas Sekretaris DPRD semakin meningkat" sebesar 4.1676 dan terendah pada pernyataan Gg.13 Praktik KKN padaSekretaris DPRD semakin berkurang sebesar 3.7039.

\section{Pengujian Asumsi SEM}

Data Interval, pengumpulan data menggunakan Skala Likert menurut Uma Sekaran Skala Likertakan menghasilkan data interval, penelitian ini memenuhi ketentuan data interval.

Kecukupan Sampel, rak 240 kuesioner disebarkan kepaua seluruh Sekretariat DPRD Provinsi, Kabupaten dan Kota di Sumatera Selatan, dari kuesioner yang kembali sebanyak 179 digunakan sebagai sampel (74,58 \%). Loehlin (1992) merekomendasikan model penelitian yang dibangun memiliki 2-4 variabel, sampel yang dibutuhkan CBSEM antara 100-200. Maka jumlah kuesioner sebanyak 179 telah memenuhi kecukupan sampel.

Hasil uji normalitas secara univariate nilai $\mathrm{cr}$ skewness sudah berada pada kisaran -2.58 sampai $+2,58$ dan secara multivariate nilai cr kortusis yang diperoleh yaitu 2,399< dari 2,58. Disimpulkan bahwa data secara univariate dan multivariate telah terdistribusi normal. 


\section{Analisis Statistika Inferensial}

Pengukuran model bertujuan untuk mengetahui apakah sebuah konstruk dapat digunakan untuk mengkonfirmasi konstruk laten. Dilakukan melalui dua tahapan yaitu melihat nilai lamda atau factor loading dan melihat bobot faktor (regression weight).

\section{Pengukuran Model Eksogen Gabungan}

Variabel eksogen terdiri dari variabel iklim organisasi dan pengembangan karir digabungkan dalam diagram model variabel eksogen. Pada CFA awalnya pengukuran model eksogen gabungan belum menghasilkan model fit. Evaluasi output regression weights hubungan semua indikator telah signifikan $<0,05$, namun pada standardized regression weights 5 indikator memiliki loading factor $<0,50$ dikeluarkan dari model. Respesifikasi model setelah mengeluarkan 5 di atas belum menghasilkan model variabel eksogen yang baik.

Selanjutnya dilakukan modifikasi indeks dengan menghubungan indeks korelasi yang memiliki covariances tinggi di atas 4,50 untuk mendapat model fit yang memenuhi cut off value. Pengolahan data menggunakan SEM Amos, model fit variabel eksogen gabungan sudah sesuai antara teori dengan data. Model telah memenuhi syarat untuk dilanjutkan pada tahap analisis selanjutnya.

\section{Pengukuran Model Endogen Gabungan}

Variabel endogen terdiri variabel motivasi kerja dan good governance digabungkan ke dalam diagram model variabel endogen. Pada CFA pengukuran awal model endogen belum memenuhi kriteria cut off value. Dari evaluasi model endogen gabungan pada output regression weights untuk melihat tingkat signifikansi
$<0.05$ dan standardized regression weights untuk melihat besaran loading factor $>0,50$.

Hasil evaluasi goodness of fit model endogen gabungan secara keseluruhan model belum fit dengan data. Perlu dilakukan respesifikasi dengan mengeluarkan indikator yang memiliki koefisien < 0,50, dilanjutkan dengan modifikasi indeks menghubungkan covariance yang memiliki indeks tinggi. Pengolahan data dengan menggunakan SEM Amos, Setelah melakukan respesifikasi model dengan mengeluarkan indikator $>0,50$, serta beberapa kali melakukan modifikasi indeks menghubungkan indeks korelasi tinggi, akhirnya mendapatkan model fit eksogen gabungan sudah baik dan sesuai dengan data serta telah memenuhi syarat untuk dilanjutkan pada tahapan analisis selanjutnya yaitu pada tahapan pengujian structural overall model.

\section{Pengujian Struktural Model}

Setelah measurement model eksogendan endogen menghasilkan fit model yang sesuai dengan data. Dilanjutkan pengujian struktural model dengan menggabungkan model eksogen dengan model endogen dalam diagram overall model. Pada respesifikasi overall model pertama model belum menghasil overall model, dari 10 kriteria terdapat 5 cut off value dapat dipenuhi. Dalam respesifikasi overall model kedua jumlah cut off value terpenuhi lebih baik.

Evaluasi overall model tahap kedua belum mendapatkan model fit, hingga perlu dilakukan modifikasi model. Pada output standardized regression weights terdapat 2 indikator yang memiliki koefisien $<0,50$ dan dikeluarkan dari 
model. Output regression weights variabel iklim organisasi, dimensi sistem manajemen hubungan variabel tidak signifikan koefisien negatif $-0,18$. Dikategorikan heywood case dan dikeluarkan dari model diikuti oleh indikatornya.

Heywood case juga ditemukan pada dimensi akuntabilitas pada variabel good governance, output standardized regression weights koefisien korelasi sebesar $1,154>1,0$ maka dimensi akuntabilitas dikeluarkan dari model bersama dengan indikatornya.

Dengan keluarnya dimensi variabel kategori heywood case dilanjutkan dengan respesifikasi dan modifications indices, sampai menghasilkan overall model yang memenuhi criteria goodness of fit berikut ini.

\section{Gambar GoF Overall Model}

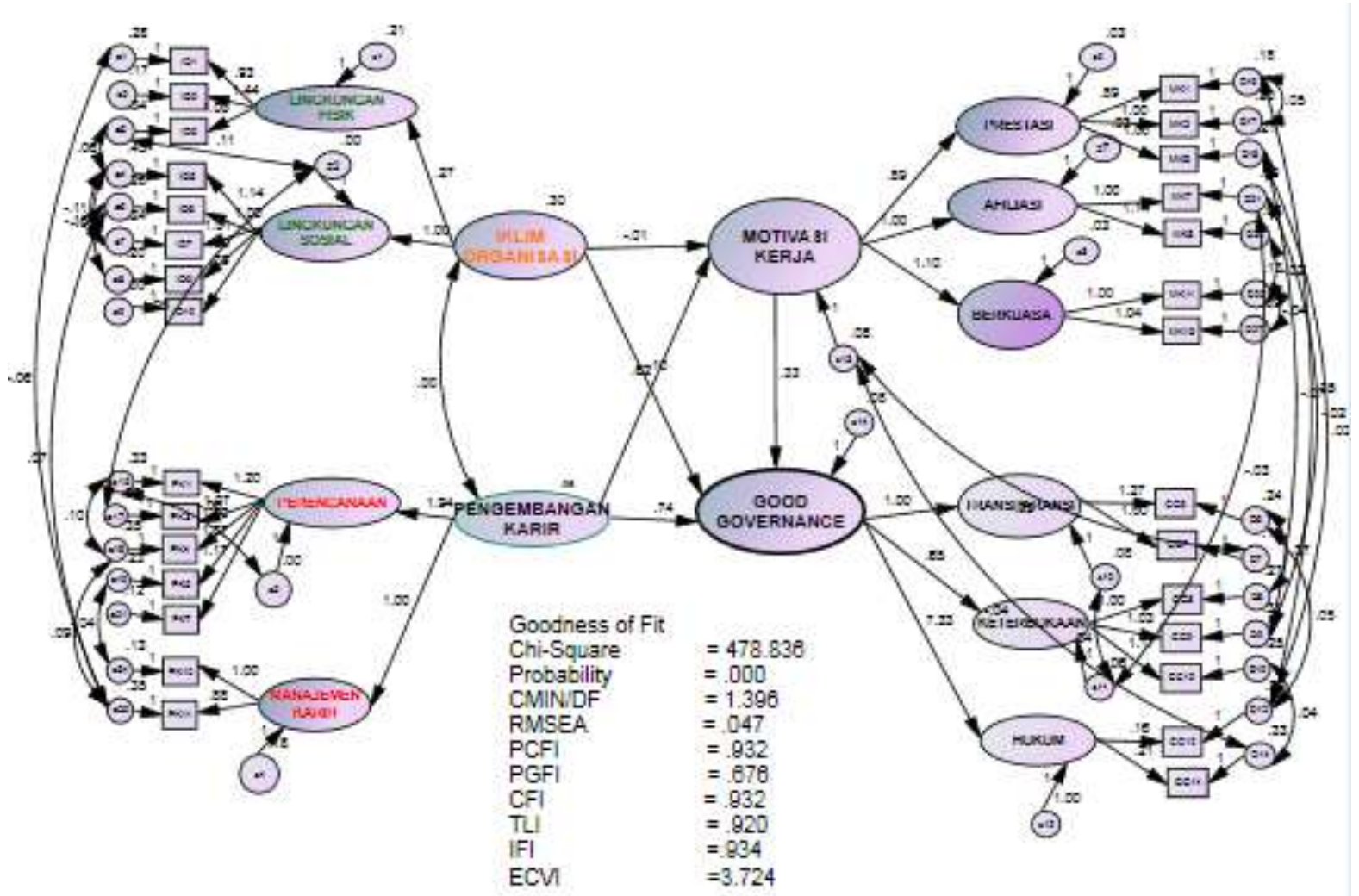

Gambar di atas menunjukkan bahwa model memiliki korelasi tinggi sehingga mendapatkan overall model fit yang baik dan sesuai dengan data. Output SEM Amos setelah melakukan respesifikasi dan modifikasi indeks mendapatkan overall model fit sesuai dengan data seperti pada gambar 2 di bawah ini. Evaluasi overall model menunjukkan bahwa konstruk dengan indikator secara keseluruhan telah memiliki hubungan sangat erat. Sehingga overall model fit telah baik. Karenanya overall model fit telah layak diterima untuk selanjutnya digunakan dalam pengujian hipotesis penelitian.

\section{Dimensi dan Indikator Dominan}

Output Amos pada standardized regression weightoverall model fit diperoleh informasi dimensi dan indikator konstruk yang dominan. Dimensi dominan adalah dimensi lingkungan kerja sosial pada 
variabel iklim organisasi $(0,995)$, dimensi perencanaan karir $(0,993)$ pada variabel pengembangan karir, dimensi kebutuhan untuk berkuasa $(0,896)$ pada variabel motivasi kerja dan dimensi aturan hukum $(0,938)$ pada variabel good governance.

Indikator dominan pada variabel iklim organisasi adalah Io.10 pejabat Sekretariat DPRD saling memberi dukungan kerja $(0,992)$, pengembangan karir pada indikator Pk.07. Semua pejabat memiliki kesempatan karir yang sama $(0,838)$, motivasi kerja pada indikator Mk.08. hubungan kerja yang baik dapat melancarkan tugas $(0,816)$ serta good governance pada indikator Gg.06 penatausahaan anggaran Sekretariat DPRD semakin tertib $(0,769)$.

\section{Uji Hipotesis}

Setelah semua asumsi SEM dipenuhi dan pengukuran struktural model menghasilkan overall model fit, dilakukan pengujian hipotesis.dengan melihat tingkat signifikansi ( $P$-value), nilai critical ratio (CR) dan determinan $R$ square pada output squared multiple correlations.

Output SEM Amos overall model fit regression weights digunakan untuk menguji tingkat signifikansi model dan koefisien estimasi persamaan struktural disarikan selengkapnya pada di bawah

\section{Tabel 1. Regression Weight}

\begin{tabular}{|c|c|c|c|c|c|c|}
\hline & & & Estimate & S.E. & C. R. & $\mathrm{P}$ \\
\hline $\begin{array}{l}\text { MOTIVASI_ } \\
\text { KERJA }\end{array}$ & & $\begin{array}{l}\text { IKLIM_- } \\
\text { ORGANISASI }\end{array}$ & -.014 & 040 & 352 & .725 \\
\hline $\begin{array}{l}\text { MOTIVASI_ } \\
\text { KERJA }\end{array}$ & & PENG_KARIR & .616 & 168 & 3.66 & $* * *$ \\
\hline GOOD_GOVERNANCE & $<-$ & $\begin{array}{l}\text { IKLIM_- } \\
\text { ORGANISASI }\end{array}$ & .104 & 051 & 2.03 & .043 \\
\hline GOOD_GOVERNANCE & $<-$ & $\begin{array}{l}\text { MOTIVASI_ } \\
\text { KERJA }\end{array}$ & .333 & 146 & 2.26 & .022 \\
\hline GOOD_GOVERNANCE & $<-$ & PENG_KARIR & .738 & 226 & 3.26 & .001 \\
\hline
\end{tabular}

\section{Output Data Diolah Dengan Amos 20}

Dari output regression weights di atas dapat dibentuk persamaan sub struktural dan persamaan struktural sebagai berikut :

Persamaan Sub Struktural :

Motivasi kerja $=-0,014 *$ iklim organisasi $+0,616 *$ pengembangan karir+errorvar 0,801 .

\section{Persamaan Struktural :}

Good governance $=0,104 *$ iklim organisasi $+0,738 *$ pengembangan karir $+0,333 *$ motivasi kerja+errorvar 0,565 .

Output squared multiple correlations untuk melihat besaran variabel eksogen dalam tabel di bawah ini :

Tabel 2. Squared Multiple Correlations

\begin{tabular}{|l|r|}
\hline \multicolumn{1}{|c|}{ Variabel } & r Square \\
\hline MOTIVASI_KERJA & .199 \\
GOOD_GOVERNANCE & .435 \\
\hline
\end{tabular}

Output Data Diolah Dengan Amos

Tabel di atas menunjukkan determinan $r$ square variabel motivasi kerja dijelaskan oleh variabel iklim organisasi dan pengembangan karir secara bersama-sama sebesar 19,9\%. Determinan $r$ square variabel good governance dijelaskan oleh variabel iklim organisasi, pengembangan karir dan motivasi kerja hanya sebesar 43,5\%. Berarti 56,5\% good governance dijelaskan oleh variasi variabel di luar dari variabel penelitian.

\section{Kesimpulan}

Analisis dan pembahasan penelitian menghasilkan temuan penelitian bahwa "Implementasi good governance dalam menerapkan aturan hukum agar penatausahaan anggaran Sekretariat DPRD semakin tertib dapat ditingkatkan melalui pelaksanaan 
kebijakan pola perencanaan karir yang memberikan kesempatanyang sama kepada seluruh pejabat untuk berprestasi" dengan kesimpulan bahwa ;

1) Tidak terdapat pengaruh Iklim organisasi terhadap motivasi kerja pejabat Sekretaris DPRD, sesuai dengan output SEM Amos pada regression weight menunjukkan tingkat signifikansi (P) 0,725>0,05 dan nilai CR sebesar $-0,352<1,96$.

2) Terdapat pengaruh pengembangan karir terhadap motivasi kerja pejabat Sekretaris DPRD, sesuai output SEM Amos pada regression weight menunjukkan tingkat signifikansi $(\mathrm{P})$ $* * *<0,05$ dan nilai CR sebesar 3.666 $>1,96$.

3) Terdapat pengaruh iklim organisasi dan pengembangan karir secara bersama-sama terhadap motivasi kerja pejabat Sekretaris DPRD, sesuai dengan output SEM Amos pada squared multiple correlations menghasilkan $r$ square determinasi $19,9 \%$ dan persamaan sub struktural motivasi kerja $=-0,014 *$ iklim organisasi $+0,616 *$ pengembangan karir + errorvar 0,801. Variabel dominan mempengaruhi motivasi kerja adalah variabel pengembangan karir dengan koefisien 0,616.

4) Terdapat pengaruh Iklim organisasi terhadap good governance pada Sekretariat DPRD, sesuai dengan output SEM Amos pada regression weight menunjukkan tingkat signifikansi $(\mathrm{P}) 0,043<0,05$ dan $\mathrm{CR}$ $2.023>1,98$

5) Terdapat pengaruh pengembangan karir terhadap good governance pada Sekretariat DPRD, sesuai dengan output SEM Amos pada regression weight menunjukkan tingkat signifikansi $(\mathrm{P})$ 0,001 $<0,05$ dan nilai CR 3,266 > 1,96.

6) Terdapat pengaruh motivasi kerja terhadap good governance pada Sekretariat DPRD, sesuai dengan output SEM Amos pada regression weight menunjukkan tingkat signifikansi $0,022<0,05$ dan $\mathrm{CR}$ nilai $2,286>1,96$.

7) Terdapat pengaruh iklim organisasi, pengembangan karir dan motivasi kerja secara bersama-sama terhadap good governance pada Sekretariat DPRD Provinsi, Kabupaten dan Kota di Sumatera Selatan, sesuai output SEM Amos pada squared multiple correlations menghasilkan $r$ square determinasi $43,5 \%$ dan persamaan struktural good governance $=0,104 *$ iklim organisasi $+0,738 *$ pengembangan karir $+0,333 *$ motivasi kerja + errorvar 0,565. Variabel dominan mempengaruhi good governance adalah pengembangan karir dengan koefisien 0,738

\section{Implikasi Kebijakan Manajerial :}

1) Kepala Daerah dan Pimpinan DPRD dapat meningkatkan motivasi kerja yang dapat berimplikasi kepada good governance pada Sekretariat DPRD Provinsi, Kabupaten dan Kota di Sumatera Selatan, melalui penyusunan program pengembangan pegawai yang menerapkan punishment and reward.

2) Kepala Daerah dan Pimpinan DPRD dalam rangka implementasi prinsipprinsip good governance dalam penatausahaan anggaran Sekretariat DPRD agar semakin tertib dapat dilakukan melalui perencanaan karir yang memberikan peluang yang sama kepada seluruh pejabat berprestasi 
disamping meningkatkan motivasi kerja pejabat agar dapat membangun hubungan kerja yang serasi.

\section{Saran Tindak Lanjut}

1) Perlu dijadwalkan pertemuan berkala antara DPRD dengan Sekretaris DPRD untuk membahas persoalan-persoalan yang dihadapi secara dini dan terarah;

2) Dalam rangka memberikan jaminan karir bagi pejabatSekretaris DPRD perlu membangun pola karir secara vertikal sebagai pegawai legislasi. Jenjang karir mulai dari Sekretaris DPRD Kabupaten/Kota, Provinsi sampai Sekretaris Jenderal DPR, Sekretaris Jenderal DPD danSekretaris Jenderal MPR.

3) Pejabat Sekretariat DPRD memiliki kemampuan menghadapi tantangan tugas, mampu mengakomodasi intervensi kepentingan politik dalam pengelolaan anggaran DPRD.

4) Perlu disusun standard operating procedure dukungan teknis operasional Sekretariat DPRD memengaruhi DPRD dan kedudukan administrasi Sekretaris DPRD dengan Kepala Daerah, sehingga mendapatkan kejelasan kedudukan, peran serta tanggungjawab pejabat Sekretaris DPRD.

5) Sekretaris DPRD perlu mengembangkan sistem informasi legislasi yang mampu memberikan informasi tentang kelegislasian sehingga membuka peluang masyarakat untuk mengakses informasi kegiatankegiatan DPRD.

6) Penerapkan punishment dan reward kepada pegawai Sekretariat DPRD akan dapat meningkatkan motivasi kerja pejabat.

7) Para pejabat Sekretaris DPRD perlu menyusun langkah untuk dapat mengeliminir praktik KKN yang dapat merugikan semua pihak.

\section{Bagi Pengembangan Ilmu Manajemen}

1) Perlu dilakukan penelitian lanjutan untuk mengevaluasi faktor-faktor eksternal iklim organisasi pada Sekretariat DPRD yang dapat mempengaruhi iklim organisasi yang berimplikasi memengaruhi peningkatan motivasi kerja pejabat.

2) Perlu dilakukan penelitian dengan lebih mendalam mengenai faktor-faktor yang dapat mendorong motivasi kerja anggota legislasi daerah dalam mengimplementasikan prinsip-prinsip good governance.

\section{Kepustakaan}

Bhattacharya, Swaha dan Mukherjee, Monimala, 2013, Organizational Climate and Work Motivation-A Study on Private Sector Organization, Calcutta, ParipexIndian Journal Of Research, Volume : 2 ( Issue :1) Januari 2013.

Dan Neogi, Debi Guha, 2006, Goal

Getting Tendencies, Work Motivation and Organizational Climate as Perceived by the Employees, Kolkata, Journal of the Indian Academy of Applied Psychologi, Vol.3, No.1, 61-65, Calcutta Univercity

Ferdinand, Augusty, 2002. Structural Equation Model, Dalam Penelitian Manajemen, Edisi 2. Semarang, Penerbit Fakultas Ekonomi Universitas Diponegoro.

2006, Metode Penelitian Manajemen, Semarang, Badan Penerbit 
Ghozali, ImaSm, 2008, Model Persamaan

Struktural, Konsep \& Aplikasi Dengan Program AMOS 16,0, Semarang, Badan Penerbit Undip.

........, 2013, Model Persamaan

Struktural, Konsep \& Aplikasi

Dengan Program AMOS 21,0,

Semarang, Badan Penerbit

Universitas Diponegoro.

Hair, el, al, 2008, Multivariate Data Analysis (6 ${ }^{\text {th }}$ ed) Eaglewood Cliffs, New York: Pearson Prentice Hall

Latan, Hengky, 2013, Model Persamaan Struktural, Teori dan Implementasi Amos 21,0, Bandung, Penerbit Alfabeta

Mangkunegara, AA. Anwar Prabu, 2009, Manajemen Sumber Daya Manusia Perusahaan, Bandung, Penerbit PT Remaja Rosdakarya. -2010, Evaluasi Kinerja Sumber Daya Manusia, Cetakan Ke Lima, Jakarta, Penerbit Refika Aditama

Moeheriono, 2010, Pengukuran Kinerja Berbasis Kompetensi, Competency Based Human Resource Management, Jakarta, Penerbit Ghalia Indonesia

Noe, A Raymond and Barry, Eirhart. 2003, Human Resource Management. New York, McGraw Hill

Rafiatun dan Masluli, 2011, Pengaruh

Iklim Organisasi dan Kompetensi Pegawai Memengaruhi Kinerja Pegawai dengan Mediasi Motivasi Pada Dinas-Dinas di Kabupaten Kudus, Jakarta, Jurnal Analisis Manajemen Vol. 5 No. 1 juli 2011.

Santoso, Singgih, 2011, Structural Equational Modeling (SEM) Konsep dan Aplikasi dengan AMOS 18, Jakarta, PT Elex Media Computindo
,2012, Analisis

SEM

Menggunakan AMOS, Jakarta, PT

Elex Media Computindo

Sedarmayanti, 2005, Tugas dan Pengembangan Sekretaris, Bandung, Penerbit Mandar Maju 2007, Good Governance (Kepemerintahan Yang baik) dan Good Corporate Governance (Tata Kelola Perusahaan Yang baik), bagian Ketiga, Bandung, Penerbit CV Mandar Maju

Sekaran, Uma, 2003, Research Methods for Bussiness, Southern Illinois, University at Carbondale

Suady, Alif, 2010, Analisis Hubungan Antara Kepemimpinan dan Lingkungan Organisasi Dengan Motivasi Pegawai Menuju Penerapan Good Governance di Direktorat Jenderal Imigrasi, Jakarta, Portal Garuda, http://lontar.ui.ac.id/opac/themes/gr een/dataIdentifier.jsp?id $=81034$

Sugiyono, 2009, Memahami Penelitian Kualitatif, Bandung, Penerbit CV Alfabeta

2012, Metode Penelitian Kombinasi (Mixed Methods), Bandung, Penerbit CV Alfabeta

Suherman, Herlan, 2009, Pengaruh Pengembangan Karir dan Motivasi Kerja Memengaruhi Kinerja Karyawan, Jurnal Manajemen Sumber Daya Manuasia, http://artikelsdm.blogs pot.com/2009/07/5-faktor-yang menentukan-karir karyawan.html

United Nation Development Programme (UNDP), 2008, DPRD Dewan Perwakilan Rakyat Daerah, Bukan Dinas Perwakilan Rakyat Daerah, Telaahan Tugas, Peran dan fungsi DPRD, Jakarta, UNDP 
Winardi, 2007, Manajemen Konflik, Konflik Perubahan dan Pengembangan, Bandung, Penerbit Mandar Maju

-------, 2008, Motivasi, Pemotivasian Dalam Manajemen, Bandung, Penerbit RadjaGrafindo Persada

Wirawan, 2007, Budaya dan Iklim Organisasi, Teori Aplikasi dan
Penelitian, Jakarta, Penerbit Salemba Empat , 2009, Evaluasi Kinerja Sumber Daya Manusia, Jakarta, Penerbit Salemba Empat 2010, Konflik dan Manajemen Konflik, Teori, Aplikasi, dan Penelitian, Jakarta, Penerbit Salemba Humanika 
